\title{
Potencialidades e fragilidades do clima de segurança do paciente: Scoping review
}

\author{
Potentialities and weaknesses of the patient safety climate: Scoping review \\ Potencialidades y fragilidades del clima de seguridad del paciente: Scoping review
}

Recebido: 22/03/2021 | Revisado: 03/04/2021 | Aceito: 06/04/2021 | Publicado: 16/04/2021

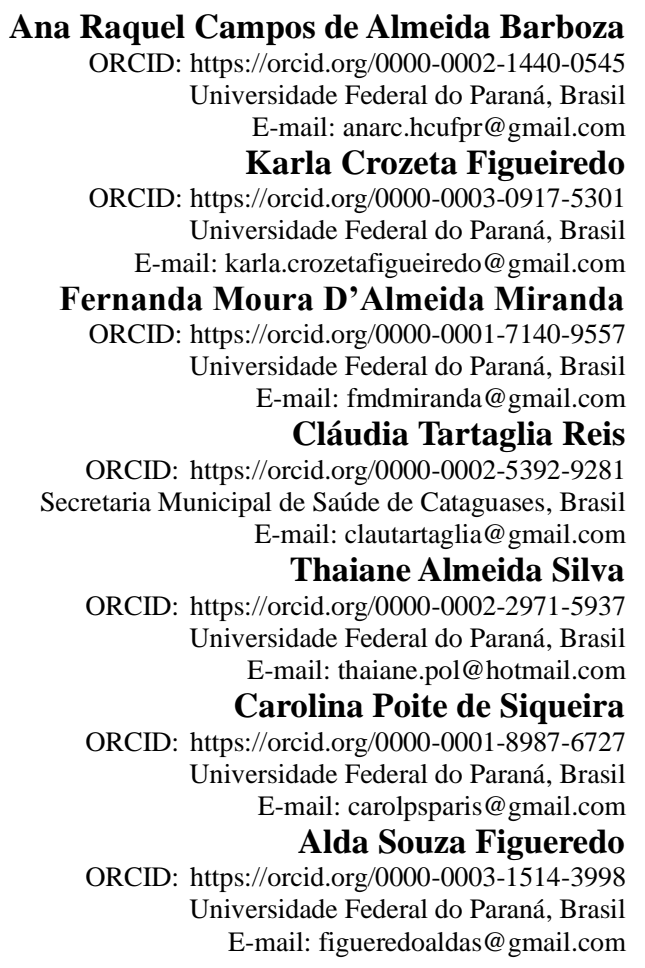

\section{Resumo}

Objetivos: mapear os estudos que utilizaram o Safety Attitudes Questionnaire em unidades críticas hospitalares; identificar os pontos fortes e fracos do clima de segurança do paciente por meio dos domínios do instrumento e relacionar as estratégias de fortalecimento para a segurança do paciente. Método: Scoping Review realizada nas bases de dados Literatura Latino-Americana e do Caribe em Ciências da Saúde, Public/Publisher Medical Literature Analysis and Retrievel System Online, Cumulative Index to Nursing and Allied Health Literature, Scopus; Web of Science, Joanna Briggs Institute Library of Systematic Reviews e outras fontes com estudos publicados entre 2006 2020 que utilizaram o instrumento Safety Attitudes Questionnaire. Resultados: Incluídos 25 estudos que avaliaram o clima de segurança no Centro Cirúrgico e Unidade de Terapia Intensiva. Evidenciou-se um clima de segurança fraco com escores abaixo do recomendado. $\mathrm{Na}$ avaliação dos escores dos seis domínios do instrumento, os dados dos estudos incluídos apontaram a "Percepção da gerência" como ponto mais fraco e a "Satisfação no Trabalho" foi o único item que apresentou escore forte. Estratégias para melhorias da qualidade da assistência e fortalecimento da segurança do paciente foram sugeridas nos estudos, como educação em serviço e implantação de sistemas de notificação de eventos adversos. Conclusão: Este estudo permitiu reconhecer os pontos fortes e fracos mapeados na literatura, o que favorece o planejamento para construção de novas práticas assistenciais em saúde, na qualidade da assistência e no desenvolvimento organizacional.

Palavras-chave: Segurança do paciente; Cultura organizacional; Atitude do pessoal de saúde; Unidades de terapia intensiva; Centros cirúrgicos.

\footnotetext{
Abstract

Objectives: to map the studies that used the Safety Attitudes Questionnaire in critical hospital units; identify the strengths and weaknesses of the patient safety climate through the domains of the instrument and relate strengthening strategies for patient safety. Method: Scoping Review carried out in the databases of Latin American and Caribbean Literature in Health Sciences, Public / Publisher Medical Literature Analysis and Retrievel System Online, Cumulative Index to Nursing and Allied Health Literature, Scopus; Web of Science, Joanna Briggs Institute Library
} 
of Systematic Reviews and other sources with studies published between 2006 - 2020 that used the Safety Attitudes Questionnaire instrument. Results: Included 25 studies that evaluated the safety climate in the Surgical Center and Intensive Care Unit. A weak security climate was evidenced with scores below the recommended. In the assessment of the scores of the six domains of the instrument, the data from the included studies pointed out "Perception of management" as the weakest point and "Job Satisfaction" was the only item that had a strong score. Strategies for improving the quality of care and strengthening patient safety have been suggested in the studies, such as in-service education and the implementation of adverse event reporting systems. Conclusion: This study made it possible to recognize the strengths and weaknesses mapped in the literature, which favors planning for the construction of new health care practices, in the quality of care and in organizational development.

Keywords: Patient safety; Organizational culture; Attitude of health personnel; Intensive care units; Surgicenters.

\section{Resumen}

Objetivos: mapear los estudios que utilizaron el Safety Attitudes Questionnaire en unidades críticas del hospital; identificar las fortalezas y debilidades del clima de seguridad del paciente a través de los dominios del instrumento y relacionar las estrategias de fortalecimiento para la seguridad del paciente. Método: Scoping Review realizada en las bases de datos de Literatura Latinoamericana y del Caribe en Ciencias de la Salud, Public/Publisher Medical Literature Analysis and Retrievel System Online, Cumulative Index to Nursing and Allied Health Literature, Scopus; Web of Science, Joanna Briggs Institute Library of Systematic Reviews y otras fuentes con estudios publicados entre 2006 y 2020 que utilizaron el instrumento Safety Attitudes Questionnaire. Resultados: Se incluyeron 25 estudios que evaluaron el clima de seguridad en el Centro Quirúrgico y Unidad de Cuidados Intensivos. Se evidenció un clima de seguridad débil con puntajes por debajo de lo recomendado. En la evaluación de las puntuaciones de los seis dominios del instrumento, los datos de los estudios incluidos señalaron la "Percepción de la gestión" como el punto más débil y la "Satisfacción laboral" fue el único ítem que tuvo una puntuación fuerte. En los estudios se han sugerido estrategias para mejorar la calidad de la atención y fortalecer la seguridad del paciente, como la educación en el servicio y la implementación de sistemas de notificación de eventos adversos. Conclusión: Este estudio permitió reconocer las fortalezas y debilidades mapeadas en la literatura, lo que favorece la planificación para la construcción de nuevas prácticas de salud, en la calidad de la atención y en el desarrollo organizacional.

Palabras clave: Seguridad del paciente; Cultura organizacional; Actitud del personal de salud; Unidades de cuidados intensivos; Centros quirúrgicos.

\section{Introdução}

A segurança do paciente busca evitar os incidentes advindos da assistência à saúde e que ocasionam danos aos pacientes (Barbosa et al., 2016). Assim, estratégias para sua melhoria estão pautadas no gerenciamento de risco e fortalecimento da cultura de segurança em nível organizacional (Macedo et al., 2019).

Para alcançá-la é preciso o desenvolvimento da cultura de segurança, definida como um conjunto de valores, atitudes, competências e comportamentos que determinam o comprometimento com a gestão de uma organização (Fan et al., 2016), e o clima de segurança relaciona-se às características mensuráveis da cultura, captadas por meio das percepções e atitudes dos indivíduos em determinado tempo e disponibiliza informações sobre o estado de segurança de um determinado grupo ou de toda a instituição (Santiago \& Turrini, 2015). Sua avaliação é considerada um passo inicial para o planejamento de estratégias de melhoria da segurança no âmbito organizacional.

Diante disto, o Safety Attitudes Questionnaire ( $S A Q)$ é um instrumento que avalia o clima de segurança do paciente nos serviços de saúde, apresentando questões de múltipla escolha distribuídas em seis domínios: Clima de Trabalho em Equipe (compreende a qualidade do relacionamento e a colaboração entre os membros de uma equipe), Satisfação no Trabalho (é a visão positiva do local de trabalho), Percepção da Gerência da Unidade e do Hospital (refere-se à aprovação das ações da gerência quanto as questões de segurança), Clima de Segurança (avalia a percepção dos profissionais quanto ao comprometimento organizacional para a segurança do paciente), Condições de Trabalho (refere-se à percepção da qualidade do ambiente de trabalho) e Percepção do Estresse (trata do reconhecimento do quanto os fatores estressores influenciam na execução do trabalho) (Carvalho et al., 2017).

As respostas de cada item seguem escala de cinco pontos de Likert, com a pontuação final variando de zero a 100, sendo zero a pior percepção do clima de segurança e 100 a melhor, considerando-se um resultado positivo uma pontuação total 
maior ou igual a 75 (Carvalho et al., 2017). Há versões do instrumento voltadas para áreas específicas, dentre elas as áreas críticas, $S A Q$ versão Centro Cirúrgico $(S A Q-O R)$ e $S A Q$ versão Unidade de Terapia Intensiva ( $S A Q$-UTI).

A segurança do paciente nessas áreas críticas envolve a complexidade das atividades realizadas, a necessidade de trabalho em equipe fortalecido, e o atendimento a pacientes graves, que necessitam monitoramento ininterrupto, recursos humanos especializados e equipamentos específicos (Minuzzi et al., 2016).

Desta forma, conhecer os fatores organizacionais e profissionais que influenciam na segurança do paciente é fundamental para subsidiar a implementação de intervenções que contribuam para o clima de segurança nas instituições (Barbosa et al., 2016)

Considerando que mensurar o clima de segurança fornece dados para a identificação de pontos fortes e fracos para a segurança do paciente, com vistas ao planejamento de ações gerenciais nos serviços e que o aprofundamento nessa temática está pautada na carência de um sumário de evidências sobre as peculiaridades do clima de segurança do paciente dentro das unidades críticas hospitalares e que abordem as questões que envolvem o gerenciamento dos serviços de saúde, objetivou-se: mapear a produção do conhecimento sobre a utilização do $S A Q$ em unidades críticas hospitalares, identificar os pontos fortes (potencialidades) e fracos (fragilidades) do clima de segurança do paciente medidos pelo $S A Q$ nas unidades críticas hospitalares e relacionar as estratégias de fortalecimento para a segurança do paciente.

\section{Metodologia}

Trata-se de uma Scoping Review (SR), elaborada segundo as recomendações do Joanna Briggs Institute. A SR concentra-se na exploração e no mapeamento da literatura sobre um determinado tema, apresenta maior flexibilidade ao compor a revisão, permitindo a utilização de uma variedade de material e fontes de busca (Peters, et al., 2020). Dessa forma, elaborou-se um protocolo, a fim de garantir o rigor do processo de pesquisa, que dispunha dos seguintes componentes: pergunta de revisão, critérios de inclusão e exclusão, estratégias para a busca, orientação para a seleção do material, análise e síntese dos dados.

A questão da revisão foi elaborada a partir do acrônimo PCC (P: população, C: conceito, C: contexto): P- Unidades críticas hospitalares; C- Pontos fortes e fracos do clima de segurança do paciente medidos pelo $S A Q$ e C- Clima de segurança do paciente nas unidades críticas. Deste modo, elaborou-se a questão de revisão: Quais são os pontos fortes e fracos do clima de segurança do paciente medidos pelo SAQ nas unidades críticas hospitalares?

Os critérios de inclusão foram: estudos empíricos e teóricos; publicados em inglês, espanhol ou português a partir do ano de 2006, incluindo estudos de caso, relatos de experiências, textos e documentos de opinião, independentemente do estágio de publicação, que avaliaram o clima de segurança do paciente em unidades críticas hospitalares. Os contextos de interesse foram relacionados à avaliação do clima de segurança utilizando o $S A Q$, elencando todos os domínios que compõem o instrumento nas unidades críticas hospitalares, e os estudos que utilizaram o $S A Q$, SAQ-OR e $S A Q-U T I$ para mensurar as dimensões do clima de segurança do paciente entre profissionais da UTI (Unidade de Terapia Intensiva), CC (Centro Cirúrgico) e salas de hemodiálise.

Os critérios de exclusão foram estudos que concentraram apenas uma categoria profissional; que não apresentaram texto completo disponível; que aplicaram ou compararam mais de um instrumento de avaliação da cultura ou clima de segurança do paciente; que focaram apenas na tradução, adaptação transcultural e validação do instrumento, sem relatar descobertas sobre o clima de segurança; que não utilizaram a aplicação de todo o $S A Q$, ou que aplicaram todo o instrumento, porém, os resultados se referiram a um único domínio; dissertações ou teses que tenham artigos extraídos já publicados em periódicos. 
Para construção das estratégias de busca, utilizou-se os seguintes descritores consultados nos Descritores em Ciências da Saúde (DeCS) e Medical Subject Headings (MESH): "Unidades de terapia intensiva"; "Intensive care units"; "Centros cirúrgicos"; "Surgicenters"; "Unidades Hospitalares de Hemodiálise"; "Hemodialysis Units"; "Hospital”; "Hospital”; Segurança do paciente"; "Patient safety"; "Cultura Organizacional"; "Organizational Culture"; "Atitude do pessoal de saúde"; "Attitude of Health Personnel”, bem como seus respectivos sinônimos e descritores não controlados. Os operadores booleanos OR, AND e NOT foram associados junto aos descritores para compor as estratégias de busca, definidas entre os meses de fevereiro a abril de 2019.

A busca foi realizada nos meses de maio e junho de 2019 e atualizada em novembro de 2020, nas bases de dados Literatura Latino-Americana e do Caribe em Ciências da Saúde (LILACS), Public/Publisher Medical Literature Analysis and Retrievel System Online (PubMed), Cumulative Index to Nursing and Allied Health Literature (CINAHL), Scopus; Web of Science, Joanna Briggs Institute Library of Systematic Reviews. As buscas na Gray Literature foram realizadas no Google Acadêmico, Plataforma ProQuest Trial, Biblioteca Digital Brasileira de Teses e Dissertações (Bdbtd), Portal Brasileiro de Publicações Científicas em Acesso Aberto - Oasisbr. O escrutínio das referências dos artigos capturados complementou o processo de busca.

Dois revisores independentes (ARCAB e TAS) realizaram a seleção dos estudos, e os dissensos analisados por um terceiro revisor $(\mathrm{KCF})$. Os dados foram extraídos pela pesquisadora principal em um instrumento contendo número de identificação do estudo, título, autores, periódico, ano e país de publicação, objetivo/finalidade, população do estudo, detalhamento metodológico, resultados, pontos fortes e fracos do clima de segurança do paciente, estratégias para fortalecimento da segurança do paciente, considerações gerais e conclusões. Ressalta-se que revisões sistemáticas do tipo $S R$ não preveem a exclusão de artigos segundo critérios de qualidade metodológica (Peters, et al., 2020).

Os dados extraídos foram sistematizados em quadros e tabelas com a apresentação dos resultados primários e, posteriormente, foi realizada a síntese narrativa dos mesmos. No que concerne aos aspectos éticos, a apreciação por Comitê de Ética em Pesquisa foi dispensada, considerando que a pesquisa foi realizada com dados secundários.

\section{Resultados}

Foram incluídos 33 estudos para leitura integral, sendo que 25 compuseram a amostra final. O processo de busca e seleção dos estudos incluídos nesta revisão estão descritos na Figura 1. 
Figura 1 - Fluxograma do processo de seleção dos estudos.

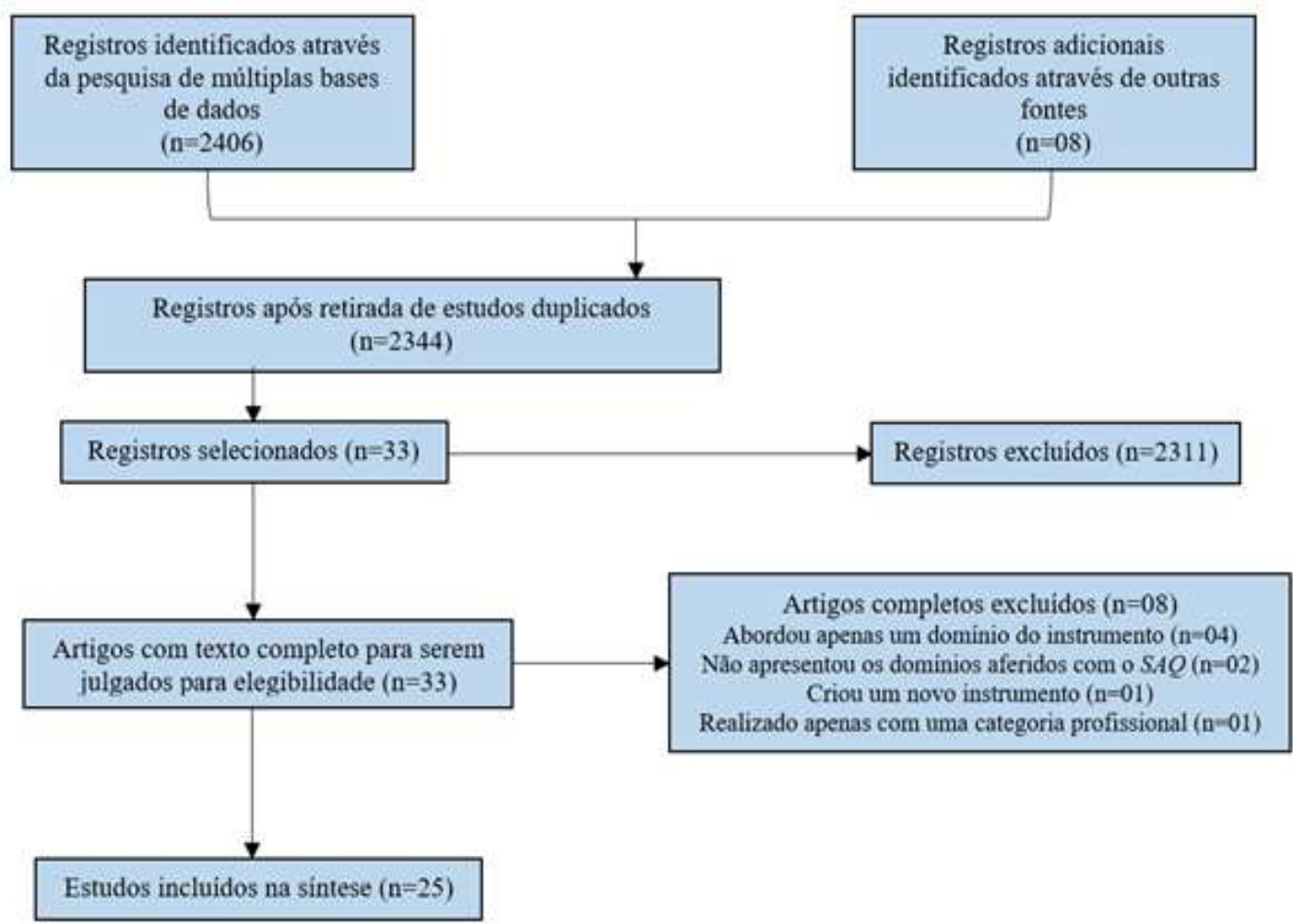

Fonte: Adaptado de TRICCO et al., (2018).

Dentre os selecionados, 23 estudos eram artigos científicos e duas dissertações de mestrado (Quadro 1). Dez estudos (40\%) foram realizados no CC (E1, E3, E4, E5, E10, E12, E18, E19, E23, E24) e 15 (60\%) em UTI (E2, E6, E7, E8, E9, E11, E13, E14, E15, E16, E17, E20, E21, E22, E25). Estudos envolvendo o uso do instrumento $S A Q$ nas salas de hemodiálise não foram identificados.

O Brasil apresentou maior número de publicações selecionadas, no total de nove estudos (36\%), seguido pelos EUA com sete publicações $(28 \%)$.

Quadro 1 - Estudos incluídos na revisão conforme título, autores, ano, periódico, volume, número e instituição de origem.

\begin{tabular}{|c|c|c|c|c|}
\hline $\mathbf{N}^{\circ}$ & Título do estudo & Autores, Ano & $\begin{array}{l}\text { Periódico, volume, } \\
\text { número }\end{array}$ & Instituição de origem, País \\
\hline E1 & $\begin{array}{l}\text { Safety culture and the } 5 \text { steps to } \\
\text { safer surgery: an intervention } \\
\text { study }\end{array}$ & Hill et al., 2015 & $\begin{array}{l}\text { British Journal of } \\
\text { Anaesthesia } \\
\text { v. } 114, \text { n. } 6\end{array}$ & $\begin{array}{l}\text { Plymouth Hospitals NHS Trust } \\
\text { Reino Unido }\end{array}$ \\
\hline E2 & $\begin{array}{l}\text { Safety culture in neonatal } \\
\text { intensive care units in the Gaza } \\
\text { Strip, Palestine: a need for policy } \\
\text { change }\end{array}$ & Abu-El-Noor et al., 2017 & $\begin{array}{l}\text { Journal of Pediatric } \\
\text { Nursing } \\
\text { v. } 33\end{array}$ & $\begin{array}{l}\text { College of Nursing, Islamic } \\
\text { University of Gaza } \\
\text { Gaza }\end{array}$ \\
\hline E3 & $\begin{array}{l}\text { Cultura de segurança no centro } \\
\text { cirúrgico de um hospital público, } \\
\text { na percepção dos profissionais de } \\
\text { saúde }\end{array}$ & Carvalho et al., 2015 & $\begin{array}{l}\text { Rev. Latino-Am. } \\
\text { Enfermagem } \\
\text { v. } 23 \text {, n. } 6\end{array}$ & $\begin{array}{l}\text { Fundação de Ensino e Pesquisa } \\
\text { em Ciências da Saúde } \\
\text { Brasil }\end{array}$ \\
\hline E4 & $\begin{array}{l}\text { Cultura de segurança entre } \\
\text { profissionais de centro cirúrgico }\end{array}$ & Cauduro et al., 2015 & $\begin{array}{l}\text { Cogitare Enferm. } \\
\text { v. } 20, \text { n. } 1\end{array}$ & $\begin{array}{l}\text { Universidade Federal do Paraná } \\
\text { Brasil }\end{array}$ \\
\hline
\end{tabular}




\begin{tabular}{|c|c|c|c|c|}
\hline E5 & $\begin{array}{l}\text { Interprofessional team } \\
\text { assessments of the patient safety } \\
\text { climate in Swedish operating } \\
\text { rooms: a cross-sectional survey }\end{array}$ & Göras et al., 2017 & BMJ Open & $\begin{array}{l}\text { School of Health Sciences, } \\
\text { Faculty of Medicine and Health, } \\
\text { Örebro University } \\
\text { Suécia }\end{array}$ \\
\hline E6 & $\begin{array}{l}\text { Measuring safety culture in } \\
\text { Palestinian neonatal intensive } \\
\text { care units using the Safety } \\
\text { Attitudes Questionnaire }\end{array}$ & Hamdan, 2013 & $\begin{array}{l}\text { Journal of Critical } \\
\text { Care }\end{array}$ & $\begin{array}{l}\text { School of Public Health, Al- } \\
\text { Quds University } \\
\text { Jerusalém }\end{array}$ \\
\hline E7 & $\begin{array}{l}\text { Patient safety culture in a Dutch } \\
\text { pediatric surgical intensive care } \\
\text { unit: An evaluation using the } \\
\text { Safety Attitudes Questionnaire }\end{array}$ & Poley et al., 2011 & $\begin{array}{l}\text { Pediatr Crit Care Med } \\
\text { v .12, n. } 6\end{array}$ & $\begin{array}{l}\text { University Rotterdam } \\
\text { Holanda }\end{array}$ \\
\hline E8 & $\begin{array}{l}\text { Perceptions of safety culture vary } \\
\text { across the intensive care units of a } \\
\text { single institution }\end{array}$ & Huang et al., 2007 & $\begin{array}{l}\text { Crit Care Med } \\
\text { v. } 35, \text { n. } 1\end{array}$ & $\begin{array}{l}\text { University of Pittsburgh } \\
\text { USA }\end{array}$ \\
\hline E9 & $\begin{array}{l}\text { Intensive care unit safety culture } \\
\text { and outcomes: a US multicenter } \\
\text { study }\end{array}$ & Huang et al., 2010 & $\begin{array}{l}\text { International Journal } \\
\text { for Quality in Health } \\
\text { Care }\end{array}$ & $\begin{array}{l}\text { University of Pittsburgh } \\
\text { USA }\end{array}$ \\
\hline E10 & $\begin{array}{l}\text { Sex differences in operating room } \\
\text { care giver perceptions of patient } \\
\text { safety: a pilot study from the } \\
\text { Veterans Health Administration } \\
\text { Medical Team Training Program }\end{array}$ & Carney et al., 2010 & $\begin{array}{l}\text { Qual Saf Health Care, } \\
\text { v. 19, p. 128e131 }\end{array}$ & $\begin{array}{l}\text { National Center for Patient } \\
\text { Safety, Vermont } \\
\text { USA }\end{array}$ \\
\hline E11 & $\begin{array}{l}\text { Safety culture in Australian } \\
\text { intensive care units: establishing a } \\
\text { baseline for quality improvement }\end{array}$ & Chaboyer et al., 2013 & $\begin{array}{l}\text { American Journal of } \\
\text { Critical Care, v. 22, n. } \\
2\end{array}$ & $\begin{array}{l}\text { University Griffith } \\
\text { Austrália }\end{array}$ \\
\hline E12 & $\begin{array}{l}\text { Operating room professionals } \\
\text { attitudes towards patient safety } \\
\text { and the influencing factors }\end{array}$ & Ongun \& Seren, 2017. & Pak J Med Sci & $\begin{array}{l}\text { Istanbul Aydin University } \\
\text { Turquia }\end{array}$ \\
\hline E13 & $\begin{array}{l}\text { Neonatal intensive care unit safety } \\
\text { culture varies widely }\end{array}$ & Profit et al., 2012 & $\begin{array}{l}\text { Arch Dis Child Fetal } \\
\text { Neonatal }\end{array}$ & $\begin{array}{l}\text { Department of Pediatrics, Baylor } \\
\text { College of Medicine, USA }\end{array}$ \\
\hline E14 & $\begin{array}{l}\text { The Safety Attitudes } \\
\text { Questionnaire as a tool for } \\
\text { benchmarking safety culture in the } \\
\text { NICU }\end{array}$ & Profit et al., 2012 & $\begin{array}{l}\text { Arch Dis Child Fetal } \\
\text { Neonatal }\end{array}$ & $\begin{array}{l}\text { Department of Pediatrics, Baylor } \\
\text { College of Medicine } \\
\text { USA }\end{array}$ \\
\hline E15 & $\begin{array}{l}\text { The culture of patient safety in an } \\
\text { Iranian intensive care unit }\end{array}$ & Abdi et al., 2015 & $\begin{array}{l}\text { Journal of Nursing } \\
\text { Management } \\
\text { v. } 23\end{array}$ & $\begin{array}{l}\text { Tehran University of Medical } \\
\text { Sciences } \\
\text { Irã }\end{array}$ \\
\hline E16 & $\begin{array}{l}\text { Measuring and comparing safety } \\
\text { climate in intensive care units }\end{array}$ & France et al., 2010 & $\begin{array}{l}\text { Medical Care } \\
\text { v. } 48, \text { n. } 3\end{array}$ & $\begin{array}{l}\text { Center for Perioperative } \\
\text { Research in Quality } \\
\text { USA }\end{array}$ \\
\hline E17 & $\begin{array}{l}\text { Health professional perspectives } \\
\text { of patient safety issues in intensive } \\
\text { care units in Saudi Arabia }\end{array}$ & Al Malki et al., 2017 & J Nurs Manag. & Monash University, Australia \\
\hline E18 & $\begin{array}{l}\text { Evaluation of patient safety } \\
\text { culture a survey of clinicians in a } \\
\text { cardiovascular operating room }\end{array}$ & Henry et al., 2012 & Innovations & $\begin{array}{l}\text { Inova Heart and Vascular } \\
\text { Institute, } \\
\text { USA }\end{array}$ \\
\hline E19 & $\begin{array}{l}\text { Avaliação da cultura de segurança } \\
\text { do paciente em Centro Cirúrgico }\end{array}$ & Correggio et al., 2014 & $\begin{array}{l}\text { Rev. SOBECC, São } \\
\text { Paulo, v. } 19, \text { n. } 2\end{array}$ & $\begin{array}{l}\text { Universidade Federal de Santa } \\
\text { Catarina, Brasil }\end{array}$ \\
\hline
\end{tabular}




\begin{tabular}{|c|c|c|c|c|}
\hline E20 & $\begin{array}{l}\text { Cultura de Segurança em } \\
\text { Unidades de Terapia Intensiva }\end{array}$ & Rei et al., 2017 & $\begin{array}{l}\text { Rev Enferm Atenção } \\
\text { Saúde [Online] } \\
\text { v. } 6, \text { n. } 2\end{array}$ & $\begin{array}{l}\text { Universidade Federal do } \\
\text { Triângulo Mineiro } \\
\text { Brasil }\end{array}$ \\
\hline E21 & $\begin{array}{l}\text { Atitudes de segurança do paciente: } \\
\text { percepções da equipe de saúde de } \\
\text { unidade de terapia intensiva de um } \\
\text { hospital de ensino do Distrito } \\
\text { Federal }\end{array}$ & Silva, 2018 & $\begin{array}{l}\text { Programa de Pós- } \\
\text { Graduação em } \\
\text { Enfermagem, } \\
\text { Dissertação de } \\
\text { Mestrado }\end{array}$ & $\begin{array}{l}\text { Universidade de Brasília } \\
\text { Brasil }\end{array}$ \\
\hline E22 & $\begin{array}{l}\text { Análise da cultura da segurança } \\
\text { entre os profissionais da Unidade } \\
\text { de Terapia Intensiva Adulto de } \\
\text { uma instituição de ensino }\end{array}$ & Gomides, 2016 & $\begin{array}{l}\text { Programa De Pós- } \\
\text { Graduação Stricto } \\
\text { Sensu Mestrado Em } \\
\text { Gestão Organizacional }\end{array}$ & $\begin{array}{l}\text { Universidade Federal De Goiás } \\
\text { Brasil }\end{array}$ \\
\hline E23 & $\begin{array}{l}\text { Clima de segurança no } \\
\text { centro cirúrgico: atitudes dos } \\
\text { profissionais de saúde }\end{array}$ & Dezordi et al., 2020 & $\begin{array}{l}\text { Cogitare enferm. } 25 \text { : } \\
\text { e65577 }\end{array}$ & $\begin{array}{l}\text { Universidade Regional do } \\
\text { Noroeste do Estado do Rio } \\
\text { Grande do Sul Brasil }\end{array}$ \\
\hline E24 & $\begin{array}{l}\text { Cultura de segurança do paciente: } \\
\text { Percepções e atitudes dos } \\
\text { trabalhadores de centro cirúrgico }\end{array}$ & Silva Júnior et al., 2020 & $\begin{array}{l}\text { Rev. SOBECC; } 25(3): \\
136-142 .\end{array}$ & Brasil \\
\hline E25 & $\begin{array}{l}\text { Cultura de segurança do paciente } \\
\text { em unidades de terapia intensiva: } \\
\text { percepção de } \\
\text { profissionais de saúde }\end{array}$ & Girão et al., 2019 & $\begin{array}{l}\text { Rev. Eletr. Enferm., } \\
\text { 21:50649. }\end{array}$ & $\begin{array}{l}\text { Universidade Estadual do Ceará } \\
\text { Brasil }\end{array}$ \\
\hline
\end{tabular}

Fonte: Autores (2021).

Quanto à amostra, nos 25 estudos (100\%) houve participação da equipe de enfermagem (auxiliares, técnicos de enfermagem e enfermeiros), médicos intensivistas, cirurgiões, anestesiologistas, bem como residentes médicos (E3, E14, E23, E24), da odontologia (E19), funcionários administrativos (E3, E14, E16, E19, E22, E24), farmacêuticos (E7, E14, E16, E25), fisioterapeutas (E8, E9, E14, E16, E17, E20, E21, E22, E25), psicólogos (E20, E21, E22, E25) e, outros membros da equipe multiprofissional (fonoaudiólogo - E20; assistente social - E2 e E25; nutricionista- E22).

O clima de segurança foi considerado fraco com escores abaixo do recomendado. A "Percepção da gerência" foi considerado como ponto mais fraco dentre os domínios, e a "Satisfação no Trabalho" e "Percepção do Estresse" foram os únicos que apresentaram escores fortes. O Quadro 2 sintetiza as médias por domínios do $S A Q$ apresentados nos estudos classificados como fortes, moderados e fracos. 
Quadro 2 - Médias por domínios do SAQ apresentados nos estudos classificados como fortes, moderados e fracos.

\begin{tabular}{|c|c|c|c|c|}
\hline $\begin{array}{l}\text { Domínios do } \\
\text { SAQ }\end{array}$ & $\begin{array}{l}\text { Versão } \\
\text { do SAQ }\end{array}$ & $\begin{array}{l}\text { Pontuação } \\
\text { Forte } \\
\text { (>75 pontos) }\end{array}$ & $\begin{array}{l}\text { Pontuação } \\
\text { Moderada } \\
\text { (70-75 pontos) }\end{array}$ & Pontuação Fraca ( $<70$ pontos) \\
\hline \multirow{3}{*}{$\begin{array}{l}\text { 1) Condições de } \\
\text { Trabalho }\end{array}$} & SAQ & NA* & NA & $\begin{array}{l}\text { Abu-El-Noor et al., 2017: 56,8 pontos; } \\
\text { Carvalho et al., 2015: 41,9 pontos; } \\
\text { Hamdan, 2013: 61,4 pontos; } \\
\text { Reis et al.2017: 55 pontos; } \\
\text { Gomides, 2016: 49,7 pontos; }\end{array}$ \\
\hline & SAQ-OR & NA & NA & $\begin{array}{l}\text { Hill et al., 2015: } 43 \text { pontos pré- } \\
\text { intervenção e 63,5 pontos pós-intervenção; } \\
\text { Goras et al., 2017: } 66,8 \text { pontos; } \\
\text { Ongun \& Intepeler, 2017: } 51,7 \text { pontos; } \\
\text { Correggio et al., 2014: 58,7 pontos; } \\
\text { Dezordi et al., 2020: } 64,8 \text { pontos. }\end{array}$ \\
\hline & SAQ-UTI & NA & $\begin{array}{l}\text { Abdi et al., 2015: } \\
71,4 \text { pontos. }\end{array}$ & France et al., 2010: 59,4 pontos. \\
\hline \multirow{3}{*}{$\begin{array}{l}\text { 2) Percepção da } \\
\text { Gerência }\end{array}$} & SAQ & NA & NA & $\begin{array}{l}\text { Abu-El-Noor et al., 2017: } 55,4 \text { pontos; } \\
\text { Carvalho et al., 2015: } 44,5 \text { pontos unidade } \\
\text { e } 34,5 \text { pontos hospital; } \\
\text { Hamdan et al., 2013: } 61,5 \text { pontos; } \\
\text { Reis et al., 2017: } 51 \text { pontos; } \\
\text { Silva, 2018: } 57 \text { pontos; } \\
\text { Gomides, 2016: } 57 \text { pontos unidade e } 42,6 \\
\text { pontos hospital; } \\
\text { Silva Júnior et. al, 2020: } 55,1 \text { pontos. }\end{array}$ \\
\hline & SAQ-OR & NA & NA & $\begin{array}{l}\text { Hill et al., 2015: } 31,4 \text { pontos pré- } \\
\text { intervenção e 45,1 pontos pós-intervenção; } \\
\text { Goras et al., 2017: 57,9 pontos; } \\
\text { Ongun \& Interpeler, 2017: } 44,5 \text { pontos; } \\
\text { Correggio et al., 2014: 53,4 pontos; } \\
\text { Dezordi et al., 2020: } 62,1 \text { pontos. }\end{array}$ \\
\hline & SAQ-UTI & NA & NA & $\begin{array}{l}\text { France et al., 2010: } 53,9 \text { pontos; } \\
\text { Malki, et al., 2017: } 47,1 \text { pontos. }\end{array}$ \\
\hline \multirow{3}{*}{$\begin{array}{c}\text { 3) } \\
\text { Reconhecimento } \\
\text { de Estresse }\end{array}$} & SAQ & $\begin{array}{l}\text { Silva Júnior et } \\
\text { al., 2020: } 77,5 \\
\text { pontos. }\end{array}$ & $\begin{array}{l}\text { Abu-El-Noor et al, } \\
\text { 2017: 71,8 pontos; } \\
\text { Carvalho et al., 2015: } \\
\text { 74,9 pontos; } \\
\text { Gomides, 2016: 73,8 } \\
\text { pontos. }\end{array}$ & $\begin{array}{l}\text { Hamdan, 2013: } 60 \text { pontos; } \\
\text { Reis, et al., 2017: } 68,1 \text { pontos. }\end{array}$ \\
\hline & SAQ-OR & NA & $\begin{array}{l}\text { Dezordi et al., 2020: } \\
73,7 \text { pontos. }\end{array}$ & $\begin{array}{l}\text { Goras et al., 2017: 62,9 pontos; } \\
\text { Ongun \& Intepeler, 2017: 33,9 pontos. }\end{array}$ \\
\hline & SAQ-UTI & NA & $\begin{array}{l}\text { Abdi et al., } 2015 \text { : } \\
70,3 \text { pontos. }\end{array}$ & France et al., 2010: 66,6 pontos. \\
\hline
\end{tabular}




\begin{tabular}{|c|c|c|c|c|}
\hline \multirow{3}{*}{$\begin{array}{l}\text { 4) Satisfação no } \\
\text { Trabalho }\end{array}$} & SAQ & $\begin{array}{l}\text { Reis et al., } \\
\text { 2017: } 81,6 \\
\text { pontos; } \\
\text { Silva, 2018: } 84 \\
\text { pontos. }\end{array}$ & $\begin{array}{l}\text { Carvalho et al., 2015: } \\
\text { 70,6 pontos; } \\
\text { Hamdan, 2013: 71,2 } \\
\text { pontos; } \\
\text { Gomides, 2016: 72,3 } \\
\text { pontos. }\end{array}$ & Abu-El-Noor et al., 2017: 66,7 pontos. \\
\hline & SAQ-OR & $\begin{array}{l}\text { Goras et. al, } \\
\text { 2017: } 78,9 \\
\text { pontos. }\end{array}$ & NA & $\begin{array}{l}\text { Hill et al., 2015: 48,9 pontos pré- } \\
\text { intervenção e } 64,4 \text { pontos pós-intervenção; } \\
\text { Correggio et al., 2014: } 58,3 \text { pontos. }\end{array}$ \\
\hline & SAQ-UTI & NA & $\begin{array}{l}\text { France et al/, 2010: } \\
71 \text { pontos; } \\
\text { Malki et al., 2017: } \\
70,3 \text { pontos. }\end{array}$ & $\begin{array}{l}\text { Poley et al., 2011: } 70,9 \text { pontos pré- } \\
\text { intervenção e } 65,6 \text { pontos pós-intervenção; } \\
\text { Abdi et al., 2015: } 68,9 \text { pontos }\end{array}$ \\
\hline \multirow{3}{*}{$\begin{array}{l}\text { 5) Clima de } \\
\text { Segurança }\end{array}$} & SAQ & NA & NA & $\begin{array}{l}\text { Abu-El-Noor et al., 2017: 61,9 pontos; } \\
\text { Carvalho, et al., 2015: 48,9 pontos; } \\
\text { Hamdan, 2013: } 64 \text { pontos; } \\
\text { Reis et al., 2017: 62,8 pontos; } \\
\text { Silva, 2018: 59 pontos; } \\
\text { Gomides, 2016: 55,8 pontos. }\end{array}$ \\
\hline & SAQ-OR & NA & NA & $\begin{array}{l}\text { Hill et al., 2015: } 57,3 \text { pontos pré- } \\
\text { intervenção e } 67,4 \text { pontos pós-intervenção; } \\
\text { Goras et al., 2017: } 66,2 \text { pontos; } \\
\text { Ongun \& Intepeler, 2017: } 53,3 \text { pontos; } \\
\text { Correggio et al., 2014: 50,6 pontos. } \\
\text { Dezordi et al., 2020: } 69,3 \text { pontos. }\end{array}$ \\
\hline & SAQ-UTI & NA & $\begin{array}{l}\text { France et. al, 2010: } \\
74,2 \text { pontos. }\end{array}$ & Abdi et al., 2015: 52,3 pontos. \\
\hline \multirow{3}{*}{$\begin{array}{l}\text { 6) Clima de } \\
\text { Trabalho em } \\
\text { Equipe }\end{array}$} & SAQ & NA & NA & $\begin{array}{l}\text { Abu-El-Noor et al., 2017: } 58,8 \text { pontos; } \\
\text { Carvalho et al., 2015: 59,1 pontos; } \\
\text { Hamdan, 2013: 65,9 pontos; } \\
\text { Reis et al., 2017: 60,9 pontos; } \\
\text { Gomides, 2016: 69,3 pontos. }\end{array}$ \\
\hline & SAQ-OR & NA & $\begin{array}{l}\text { Goras et al., } 2017 \text { : } \\
71,7 \text { pontos. }\end{array}$ & $\begin{array}{l}\text { Ongun \& Intepeler, 2017: } 59,2 \text { pontos; } \\
\text { Correggio et al., 2014: } 64,3 \text { pontos; } \\
\text { Dezordi et al., 2020: } 36,2 \text { pontos. }\end{array}$ \\
\hline & SAQ-UTI & NA & $\begin{array}{l}\text { France et al., 2010: } \\
72,2 \text { pontos. }\end{array}$ & $\begin{array}{l}\text { Poley et al., 2011: } 69 \text { pontos pré- } \\
\text { intervenção e } 69 \text { pontos pós-intervenção; } \\
\text { Abdi et al., 2015: } 59 \text { pontos }\end{array}$ \\
\hline
\end{tabular}

Legenda: NA - Não apresentado resultado correspondente a este tópico nos estudos incluídos. Fonte: Autores (2021).

Quanto à notificação de eventos adversos (EA), os resultados do E2 demonstraram baixos níveis de notificação nas UTIs 58,9\% dos participantes não relataram nenhum evento nos últimos 12 meses), sendo que, os médicos (79,8\%) relataram pelo menos um evento no último ano, e enfermeiros apenas 34,1\%. No E6 dois terços dos participantes acreditam que eles são encorajados a relatar os EA e o sistema trata-os adequadamente, e 41,7\% acreditam ser possível discutir erros nas UTIs.

Os estudos E4; E9; E10 e E11 apresentaram os resultados dos domínios por categoria profissional. Em um comparativo entre enfermeiros e médicos, notou-se a prevalência das pontuações significativamente mais baixas dentre os enfermeiros (E8, E9, E10, E11). 
Estratégias para melhorias da qualidade da assistência e fortalecimento da segurança do paciente foram sugeridas nos estudos E2, E6, E7, E8, E13, E15 e E18, porém, nenhum estudo relatou que estas estratégias foram implementadas nos serviços de saúde, o que aponta a necessidade de estudos nessa temática.

Dentre as recomendações extraídas dos estudos destacam-se: Implementação eficaz e eficiente da cultura de segurança de programas de intervenção personalizados de acordo com as necessidades individuais do setor; educação em serviço da equipe; sistemas de relatórios de notificação de EA; fim da cultura punitiva por erros; disponibilização de informações rotineiras à equipe para execução de tarefas; melhoria da percepção da gestão por meio da introdução de rodadas de liderança; adequação do dimensionamento de pessoal para lidar com as cargas de trabalho; redução da quantidade de formulários a serem preenchidos; desenvolvimento do programa de gerenciamento de fadiga na unidade; melhorar a conformidade com a higiene das mãos, para redução dos índices de infecção; ajustes de salários dos profissionais de saúde.

No E7, a melhoria da comunicação foi a recomendação mais listada na seção aberta do $S A Q$, particularmente entre enfermeiros e médicos. As UTIs não apresentaram escores uniformes entre as dimensões e no E8 e E17 os diretores de enfermagem superestimaram os escores de cultura de segurança de seus funcionários, particularmente para as dimensões "clima de trabalho em equipe" e as "condições de trabalho" no E8 e em todas as dimensões para o E17. No E11, a avaliação dos diretores de enfermagem e enfermeiros assistenciais foram semelhantes em suas percepções sobre o clima de segurança, exceto nas avaliações do gerenciamento hospitalar, ao quais os gerentes apresentaram valores mais baixos.

\section{Discussão}

A cultura e o clima de segurança são reconhecidos como umas das principais condições para a segurança do paciente. Realizar a avaliação do status quo em diferentes domínios é o primeiro passo para melhorá-los, compreendendo que, uma unidade com pontuação alta em um fator pode apresentar pontuação ruim em outro (Poley et al., 2011; Huang et al., 2007). A avaliação multidimensional é importante, pois a concentração em um fator pode levar à negligência de outros (Huang et al., 2007).

Observa-se que o clima de segurança variou nos estudos incluídos na SR, de acordo com cada dimensão, unidade (CC e UTI) e categoria profissional. No que se refere às dimensões do $S A Q$, os resultados revelaram baixos níveis de atitudes de segurança em todas elas, apontando oportunidades para promoção da segurança do paciente, por meio da implementação de ações de melhoria, particularmente nas dimensões com pontuações abaixo do esperado.

A percepção da gerência pelos profissionais é fundamental para a promoção da segurança do paciente, pois, reflete o grau de concordância destes indivíduos sobre as ações da gerência ou da administração do hospital e os baixos escores indicam o distanciamento entre equipe e seus superiores, em relação ao diálogo sobre questões de segurança do paciente (Rigobello et al., 2012).

Os gerentes precisam mostrar responsabilidade compartilhada com a equipe de saúde, fornecendo apoio para aumentar a conscientização sobre a segurança do paciente nas unidades críticas (Hamdan, 2013). Um dos estudos concluiu que os profissionais consideram que as ações gerenciais são o principal fator contribuinte para a fragilidade da cultura de segurança (Silva Júnior et al., 2020).

Estudo realizado em 2019, que avaliou o clima de segurança do paciente na perspectiva dos profissionais da equipe de saúde de um hospital, revelou escore baixo $(62,1)$ nesta dimensão, demonstrando a insatisfação dos profissionais e uma visão negativa quanto às ações da gerência frente às questões de segurança, o que reflete o fato de os profissionais considerarem a administração não preocupada com o bem-estar dos pacientes e da própria instituição (Magalhães et al.,2019).

As condições de trabalho a que os profissionais estão expostos representam potenciais estímulos de estresse e tensão. Estudo que comparou o clima de segurança em instituições hospitalares públicas e privadas apontou diferença no clima de 
segurança entre os hospitais avaliados, com pontuação positiva neste domínio no serviço privado $(79,0)$ enquanto nas instituições filantrópicas ficou abaixo $(73,5)$, entretanto, estes valores apresentaram médias maiores que os estudos realizados nas unidades críticas incluídas nesta pesquisa (Kolankiewicz et al., 2017).

A percepção de que as pessoas tomam boas decisões não importando o estresse sob elas não é verdadeira, visto que afeta os resultados na assistência à saúde, bem como, a alta carga de trabalho e a privação do sono diminuem o desempenho e aumentam a ocorrência de EA (Poley et al., 2011). Estudo brasileiro que aplicou o $S A Q$ e outro instrumento em uma UTI, apontou a percepção do estresse como uma das dimensões pior avaliadas (Santiago \& Turrini, 2015), contudo, outro estudo realizado em todo ambiente hospitalar demonstrou, escore moderado neste domínio ( 74,3 pontos), destacando que os profissionais de nível superior tiveram maior reconhecimento dos fatores estressores que influenciam na execução do trabalho, com escores maiores quando comparado aos profissionais de nível médio (Carvalho et al., 2017).

A percepção positiva no domínio "satisfação no trabalho" é diretamente relacionada com à qualidade do cuidado; as organizações que possuem profissionais insatisfeitos com o trabalho apresentam maiores taxas de rotatividade e de evento adverso, como erros de medicação, infecções associadas aos cuidados de saúde e quedas (Toso et al., 2016). Resultado similar aponta que um bom score para satisfação no trabalho indica uma cultura de segurança positiva para este domínio (Pagani et al., 2019).

Supõe-se que para o desenvolvimento do clima de trabalho em equipe seja fundamental que profissionais de saúde incorporem e aprimorem a ideia da responsabilidade coletiva e compartilhada (Wegner et al., 2016). O trabalho em equipe caracteriza uma cultura de boa comunicação visto que quando deficitária causa desarticulação das atividades multidisciplinares, principalmente no CC e na UTI, sendo assim, o desenvolvimento de comunicação efetiva reflete a colaboração mútua entre profissionais, propiciando resultados positivos, como a satisfação com o trabalho e a eficiência nas atividades (Hamdan, 2013). Portanto, o clima de segurança inclui a previsibilidade do comportamento de outras pessoas.

Há de se considerar que a percepção do domínio clima de segurança, assim como nos demais, pode ser avaliado de forma diferente por categorias profissionais distintas, como no estudo feito em um CC que apontou no domínio clima de segurança uma média menor entre a equipe médica $(65,08)$, quando comparada com a da enfermagem $(74,79)$, estando este próximo do escore positivo (Dezordi et al., 2020).

A avaliação negativa de um domínio referente à segurança do paciente oportuniza melhoria para questões gerenciais e, quando a gestão da organização está comprometida com a segurança, fornece apoio e recursos adequados, promovendo melhoria dos esforços operacionais (equipamentos, procedimentos, seleção, capacitação e horários de trabalho) para melhorar a segurança do paciente (Pagani et al., 2019).

As estratégias apresentadas nos estudos desta revisão são ações essenciais para o fortalecimento da segurança do paciente, podendo ser implementadas a curto e longo prazo. Contudo, pela sobrecarga de trabalho, dimensionamento de pessoal inadequado, e da cultura organizacional resistente a mudanças, os gestores enfrentam dificuldades para a implementação dessas práticas (Profit et al., 2012).

Dentre as estratégias apontadas, sugere-se que a cultura de segurança seja avaliada continuamente, para que ações que possibilitem a implantação de uma cultura justa sejam desenvolvidas, incentivando a cultura de relato e notificação e de aprendizagem contínua, reconhecendo-se os erros, investigando-os, permitindo, assim, encontrar as soluções mais adequadas (Girão, et al., 2019).

Uma boa comunicação com a equipe é uma característica de líderes fortes, quando o gestor proporciona momentos de escuta para que a equipe exponha a sua opinião, permite que os seus membros se sintam parte do processo, deste modo, valorizar os saberes e as experiências dos indivíduos é importante para promover a segurança da assistência, pois toda mudança requer participação de todos os níveis da organização (Carvalho et al., 2015). 
Elaborar ações de melhoria não é um processo simples ou isolado, torna-se necessário compreender a complexidade do local e refletir sobre as reais necessidades do serviço para propiciar segurança com qualidade e o cuidado seguro (Macedo et al., 2019).

\section{Conclusão}

Os objetivos da SR e a questão de pesquisa foram respondidos. No mapeamento da produção do conhecimento sobre a utilização do SAQ em unidades críticas hospitalares, foram incluídos 25 estudos, que apontaram como ponto forte, para o clima de segurança do paciente, somente o domínio "Satisfação no Trabalho". Demais domínios que compõem o $S A Q$ apresentaram médias moderadas a fracas na literatura mapeada, no qual a "Percepção da Gerência" apresentou o menor escore na média dos estudos.

Relacionar as estratégias de fortalecimento para a segurança do paciente se configura em uma potencial contribuição desta SR para a prática, visto que embora as recomendações mapeadas nos estudos não tenham sido aplicadas, apreende-se que elas podem ser aplicadas unidades críticas antes mesmo da realização de estudos de avaliação de clima de segurança local, visto que versam sobre a comunicação, liderança, fim da cultura positiva, educação em serviço, entre outras competências gerenciais, as quais são reconhecidas como estruturais aos planos de segurança do paciente.

Dessa forma, espera-se que os resultados encontrados nesta SR auxiliem os gestores, a fim de direcionar para a reflexão e implementação de ações individuais para cada unidade crítica, com intuito de fortalecer o clima de segurança do paciente, considerando um compromisso integral de todos os níveis da organização (estratégico, político e operacional), motivando os profissionais como parte inerente deste processo.

As limitações desta pesquisa foram a não utilização de busca na base de dados EMBASE devido sua indisponibilidade no ambiente acadêmico, inclusão de apenas duas unidades críticas hospitalares, não ter localizado nenhum artigo em espanhol que atendessem aos objetivos e critérios de inclusão propostos. $S R$ não requer uma análise da qualidade metodológica de cada estudo incluído, mas este é um fator limitador para o apontamento dos resultados do estudo.

Por fim, conclui-se que, avaliar o clima de segurança é ferramenta gerencial inicial, que permite reconhecer os pontos fortes e fracos para um diagnóstico situacional, fornecendo subsídios para o planejamento na construção de novas práticas assistenciais em saúde, qualidade da assistência e desenvolvimento organizacional.

\section{Referências}

Abdi, Z., Delgoshaei, B., Ravaghi, H., Abbasi, M., \& Heyrani, A. (2015). The culture of patient safety in an Iranian intensive care unit. J Nurs Manag. 23(3), 333-345. doi.org/10.1111/jonm.12135.

Abu-El-Noor, N. I., Hamdan, M. A., Abu-El-Noor, M. K., Radwan, A-KS., \& Alshaer, A. A. (2017). Safety culture in neonatal intensive care units in the gaza strip, palestine: a need for policy change. J Pediat Nurs. 33, 76-82. doi.org/10.1016/j.pedn.2016.12.016.

Al Malki, A., Endacott, R., \& Innes, K (2018). Health professional perspectives of patient safety issues in intensive care units in Saudi Arabia. J Nurs Manag. 26(2), 209-218. doi.org/10.1111/jonm.12536.

Barbosa, M., Floriano, D., Oliveira, K., Nascimento, K., \& Ferreira, L. (2016). Patient safety climate at a private hospital. Texto Contexto Enferm. 25(3), e1460015. doi.org/10.1590/0104-07072016001460015.

Carney, B. T., Mills, P. D., Bagian, J. P., \& Weeks, W. B. (2010). Sex differences in operating room care giver perceptions of patient safety: a pilot study from the Veterans Health Administration Medical Team Training Program. Qual Saf Health Care. 9(2), 128-131. dx.doi.org/10.1136/qshc.2008.028233.

Carvalho, P. A., Göttems, L. B. D., Pires, M. R. G. M., \& Oliveira, M. L. C. (2015). Safety culture in the operating room of a public hospital in the perception of healthcare professionals. Rev Latino-Am Enfermagem. 23(6), 1041-1048. doi.org/10.1590/0104-1169.0669.2647.

Carvalho, R. E. F. L., Arruda, L. P., Nascimento, N. K. P., Sampaio, R. L., Cavalcante, M. L. S. N., \& Costa, A. C. P. (2017). Assessment of the culture of safety in public hospitals in Brazil. Rev Latino-Am Enferm. 25:e2849. doi.org/10.1590/1518-8345.1600.2849.

Cauduro, F. L., Sarquis, L. M., Sarquis, L. M. M., \& Cruz, E. D. A. (2015). Safety culture among surgical center professionals. Cogitare Enferm; 20(1). doi.org/10.5380/ce.v20i1.36645. 
Chaboyer, W., Chamberlain, D., Hewson-Conroy, K., Grealy, B., Elderkin, T., Brittin, M., McCutcheon, C., Longbottom, P., \& Thalib, L. (2013) Cne article: safety culture in Australian intensive care units: establishing a baseline for quality improvement. Am J Crit Care. 22(2), 93-102. doi.org/10.4037/ajcc2013722.

Correggio, T. C. D., Amante, L. N., \& Barbosa, S. F. F. (2014). Avaliação da cultura de segurança do paciente em Centro Cirúrgico. Rev SOBECC. 19(2), 6773. doi.org/10.4322/sobecc.2014.012.

Dezordi, C. C. M., Benett, S. A. W., Tanaka, A. K da R., Benetti, E. R. R., Treviso, P., Carenato, R. C. A., \& Stumm, E. M. F. (2020). Safety climate in the operation room: attitudes of health professionals. Cogitare enferm., 25: e65577. doi.org/10.5380/ce.v25i0.65577.32

Fan, C. J., Pawlik, T. M., Daniels, T., Vernon, N., Banks, K., Westby, P., Wick, E. C., Sexton, J. B., \& Makary, M. A. (2016) Association of Safety Culture with Surgical Site Infection Outcomes. J Am Coll Surg. 222(2),1228. doi.org/10.1016/j.jamcollsurg.2015.11.008.

France, D. J., Greevy, R. A., Liu, X., Burgess, H., Dittus, R. S., Weinger, M. B., \& Speroff, T. (2010) Measuring and comparing safety climate in intensive care units. Med Care. 48(3), 279-284. doi.org/10.1097/mlr.0b013e3181c162d6.

Girão A. L. A., Lacerda, A. J. A., Carvalho, L. S., Lousada, L. M., Nascimento, K. M. B., Cruz, K. T., Carvalho, R. E. F. L (2019). Patient safety culture in intensive care units: the perceptions of health professionals. Rev. Eletr. Enferm. 21: 50649. doi.org/10.5216/ree.v21.50649

Gomides, M. D. A (2016). Análise da cultura da segurança entre os profissionais da unidade de terapia intensiva adulto de uma instituição de ensino. Catalão. Universidade Federal de Goiás.

Göras, C., Unbeck, M., Nilsson, U., \& Ehrenberg, A. (2017). Interprofessional team assessments of the patient safety climate in Swedish operating rooms: a cross-sectional survey. BMJ Open. 7(9), e015607. dx.doi.org/10.1136/bmjopen-2016-015607.

Hamdan, M. (2013). Measuring safety culture in Palestinian neonatal intensive care units using the Safety Attitudes Questionnaire. J Crit Care; 28(5), 886.e7886.e14. doi.org/10.1016/j.jcrc.2013.06.002

Henry, L., Hunt, S. L., Kroetch, M., Yang, Y. T. (2012). Evaluation of patient safety culture: a survey of clinicians in a cardiovascular operating room. Innovations.7(5), 328-337. doi.org/10.1097\%2Fimi.0b013e31827e3625.

Hill, M. R., Roberts, M. J., Alderson, M. L., \& Gale, T. C. E. (2015). Safety culture and the 5 steps to safer surgery: an intervention study. Br J Anaesth. 114(6), 958-962. doi.org/10.1093/bja/aev063.

Huang, D. T., Clermont, G., Sexton, B. J., Karlo, C. A., Miller, R. G., Weissfeld, L. A., Rowan, K. M., \& Angus, D. C (2007). Perceptions of safety culture vary across the intensive care units of a single institution*: Crit Care Med. 35(1), 165-976. 10.1097/01.CCM.0000251505.76026.CF.

Huang, D. T., Clermont, G., Kong, L., Weissfeld, L. A., Sexton, J. B., Rowan, K. M, \& Angus, D. C. (2010). Intensive care unit safety culture and outcomes: a US multicenter study. Int J Qual Health Care. 22(3), 151-161. doi.org/10.1093/intqhe/mzq017.

Kolankiewicz, A. C. B., Loro, M. M., Schmidt, C. R., Santos, F. P., Bandeira, V. A. C., \& Magnago, T. S. B. S (2017). Patient safety climate among nursing staff: contributing factors. Acta Paul Enferm. 30(5), 531-537. doi.org/10.1590/1982-0194201700076.

Macedo, S. M. K., Barboza, A. R. C. A., Borges, F., Figueiredo, K. C., Peres, A. M., \& Assis, F. (2019). Patient safety culture: evaluation of nurses in primary health care. Enferm Glob. 18(4), 365-397. doi.org/10.6018/eglobal.18.4.352261.

Magalhães, F. H de L., Pereira, I. C de A., Luiz, R. B., Barbosa, M. H., \& Ferreira, M. B. G. (2019). Patient safety atmosphere in a teaching hospital. Rev Gaúcha Enferm. 40(spe):e20180272. doi.org/10.1590/1983-1447.2019.20180272.

Minuzzi, A. P., Salum, N. C., Locks, M. O. H., Amante, L. N., \& Matos, E. (2016). Contributions of healthcare staff to promote patient safety in intensive care. Esc Anna Nery. 20(1). doi.org/10.5935/1414-8145.20160017.

Ongun, P., \& Seren, S. I. (2017). Operating room professionals' attitudes towards patient safety and the influencing factors. Pak J Med Sci. [Internet]. 33(5). doi.org/10.12669/pjms.335.13615.

Pagani, S., Crozeta, K. F., Crisigiovani, A. B. R. (2019). Culture of patient safety: evalutation of nurses. Rev Rene. 20: e39782. doi.org/10.15253/21756783.20192039782.

Peters, M. D. J., Godfrey, C., McInerney, P., Munn, Z., Tricco, A. C., \& Khalil, H. (2020) Chapter 11: Scoping Reviews. Adelaide. Joanna Briggs Institute Reviewer's Manual. https://reviewersmanual.joannabriggs.org/.

Poley, M. J., van der Starre, C., van den Bos, A., van Dijk, M., \& Tibboel, D. (2011). Patient safety culture in a Dutch pediatric surgical intensive care unit: An evaluation using the Safety Attitudes Questionnaire: Pediatr Crit Care Med. 12(6), e310-6. doi.org/10.1097/pcc.0b013e318220afca.

Profit, J., Etchegaray, J., Petersen, L. A., Sexton, J. B., Hysong, S. J., Mei, M., \& Thomas, E. J. (2012). Neonatal intensive care unit safety culture varies widely. Arch Dis Child Fetal Neonatal Ed. 97(2), 120-126. doi.org/10.1136/archdischild-2011-300635.

Profit, J., Etchegaray, J., Petersen, L. A., Sexton, J. B., Hysong, S. J., Mei, M., \& Thomas, E. J. (2012). The Safety Attitudes Questionnaire as a tool for benchmarking safety culture in the NICU. Arch Dis Child Fetal Neonatal. 97(2), 127-132. doi.org/10.1136\%2Farchdischild-2011-300612.

Reis, F. F. P., Oliveira, K. F., Luiz, R. B., Barichello, E., Cruz, L. F., \& Barbosa, M. H. (2017). Cultura de segurança em unidades de terapia intensiva. Rev Enferm Atenção Saúde. 6(2). doi.org/10.18554/reas.v6i2.1842.

Rigobello, M. C. G., Carvalho, R. E. F. L., Cassiani, S. H. D. B., Galon, T., Capucho, H. C., \& Deus, N. N. (2012). The climate patient safety: perception of nursin professionals*. Acta Paul Enferm. 25(5), 728-735. doi.org/10.1590/S0103-21002012000500013. 
Research, Society and Development, v. 10, n. 4, e41110414167, 2021

(CC BY 4.0) | ISSN 2525-3409 | DOI: http://dx.doi.org/10.33448/rsd-v10i4.14167

Santiago, T. H. R., \& Turrini, R. N. T. Organizational culture and climate for patient safety in Intensive Care Units (2015). Rev esc enferm USP. 49, 123-130. doi.org/10.1590/S0080-623420150000700018.

Silva, V. F. (2018). Atitudes de segurança do paciente: Percepções da equipe de saúde de unidade de terapia intensiva de um hospital de ensino do Distrito Federal. Brasília. Universidade de Brasília.

Silva Júnior, J. F., Jesus Júnior, P. J., Carvalho, T. A., Aguiar, M. P. C., Mendonça, S. M. D., \& Lordelo, D. S. (2020). Patient safety culture: perceptions and attitudes of surgical centers workers. Rev. SOBECC. 25(3), 136-142. doi.org/10.5327/Z1414-4425202000030003.

Tricco, A. C., Lillie, E., Zarin, W., O'Brien, K. K., Colquhoun, H., Levac, D., Moher, D., Peters, M. D., Horsley, T., Weeks, L., Hempel, S., Akl, E. A., Chang, C., McGowan, J., Stewart, L., Hartling, L., Aldcroft, A., Wilson, M. G., Garritty, C., Lewin, S., Godfrey, C. M., Macdonald, M. T., Langlois, E. V., Weiser, K. S., Moriarty, J., Clifford, T., Tunçalp, O., \& Straus, S. (2018). Extension for Scoping Reviews (PRISMA-ScR): Checklist and Explanation. Annals of Internal Medicine.169(7). doi.org/10.7326/M18-0850.

Toso, G. L., Golle, L., Magnago, T. S. B. de S., Herr, G. E. G., Loro, M. M., Aozane, F., \& Kolankiewicz, A. C. B. (2016). Patient safety culture in hospitals within the nursing perspective. Rev Gaúcha Enferm. 37(4). doi.org/10.1590/1983-1447.2016.04.58662.

Wegner, W., Silva, S. C., Kantorski, K. J. C., Predebon, C. M., Sanches, M. O., \& Pedro, E. N. R. (2016). Education for culture of patient safety: Implications to professional training. Escola Anna Nery. 20(3). doi.org/10.5935/1414-8145.20160068. 